\title{
EPSL
}

Earth and Planetary Science Letters 132 (1995) 141-155

\section{Paleomagnetism and magnetic fabrics from the Springdale and Wigwam Redbeds of Newfoundland and their implications for the Silurian paleolatitude controversy}

\author{
John Stamatakos, Angela M. Lessard, Ben A. van der Pluijm, Rob Van der Voo \\ Department of Geological Sciences, University of Michigan, Ann Arbor, MI, USA
}

Received 17 November 1994; accepted after revision 7 March 1995

\begin{abstract}
In many mobile belts, paleomagnetic directions from clastic sedimentary rocks are typically shallower than directions from associated igneous rocks. This discurdance raises questions about the reliability of sedimentary rocks and can lead to controversial paleogeographic reconstructions. In Newfoundland, the controversy over Silurian paleogeography arises from a difference between results from clastic redbeds (with anomalously shallow directions that place Newfoundland at the paleoequator in the Silurian) and coeval epicontinental volcanics (with steeper directions that place Newfoundland at a more southerly paleolatitude). This study tests the possibility that the anomalously shallow redbed directions are the result of internal strain or inclination error related to deposition. We specifically compare coarse- and fine-grained lithologies under the assumption that such remanence-altering effects will be different in rocks with differing mechanical competence.

We show that inclinations correlate with lithologic variations, but in a manner opposite to that predicted for the accumulation of internal strain. Based upon a strict set of demagnetization criteria, clearly defined single-component characteristic directions are only observed in the finer grained sandstones. These well-determined directions yield a pre-folding and pre-rotational dual polarity magnetization that places Newfoundland at a paleolatitude of $23^{\circ}(\mathrm{S}) \pm 9^{\circ}$ in the Silurian. This revised paleolatitude is consistent with the volcanic results and with the paleolatitude predicted for Newfoundland from the North American reference path. In contrast, coarse-grained sandstones yield shallower directions that appear to be composites of opposite polarity magnetizations or weakly defined directions with strongly contaminating overprints. Because the shallow magnetizations in the coarser grained samples may have originated as a depositional remanence, we also suspect inclination error related to deposition. The degree of inclination error is consistent with values predicted for redbeds from previously published experimental results. These observations suggest that grain-size considerations are important in assessing the reliability of redbed magnetizations. Recognition of the relationship between grain size and remanence acquisition allows us to resolve the Silurian paleolatitude controversy for Newfoundland.
\end{abstract}

\section{Introduction}

Recent paleomagnetic studies of coeval volcanic and red clastic rocks from the Atlantic Provinces in Canada yield seemingly inconsistent results that have triggered a controversy over the Silurian paleolati- tude of Newfoundland and possibly Laurentia. Paleomagnetic directions from volcanic units (mainly pillow basalts) of the Botwood Group [1,2] and the Springdale Group [3] show intermediate inclinations that place Newfoundland at a moderate southerly paleolatitude $\left(\sim 25^{\circ}\right)$ in the Silurian. This paleolati- 
tude is similar to that predicted for Newfoundland from the North American apparent polar wander (APW) path [4] and supports the conclusion based on geologic data that there was no significant displacement between North America and the accreted fragments of Iapetus after middle Silurian time [5].

In contrast, paleomagnetic directions from siliciclastic redbeds of the King George IV Lake area [6], the Wigwam Formation of the Botwood Group [1,7] and the Springdale Group $[3,8]$ reveal a range of shallower inclinations that place Newfoundland at or near the equator in the Silurian. Unlike the paleolati- tude estimates from the volcanic rocks, an equatorial paleolatitude for Newfoundland is difficult to reconcile within geological constraints or established Silurian paleogeography and requires either a dextral offset up to $2500 \mathrm{~km}$ between central Newfoundland and Laurentia or a modification of the North American APW reference path that would keep Laurentia near the paleoequator throughout much of the Paleozoic [8]. Until this controversy is resolved, Silurian paleogeographic reconstructions for Newfoundland and possibly for Laurentia remain in doubt.

At the core of the controversy are questions about

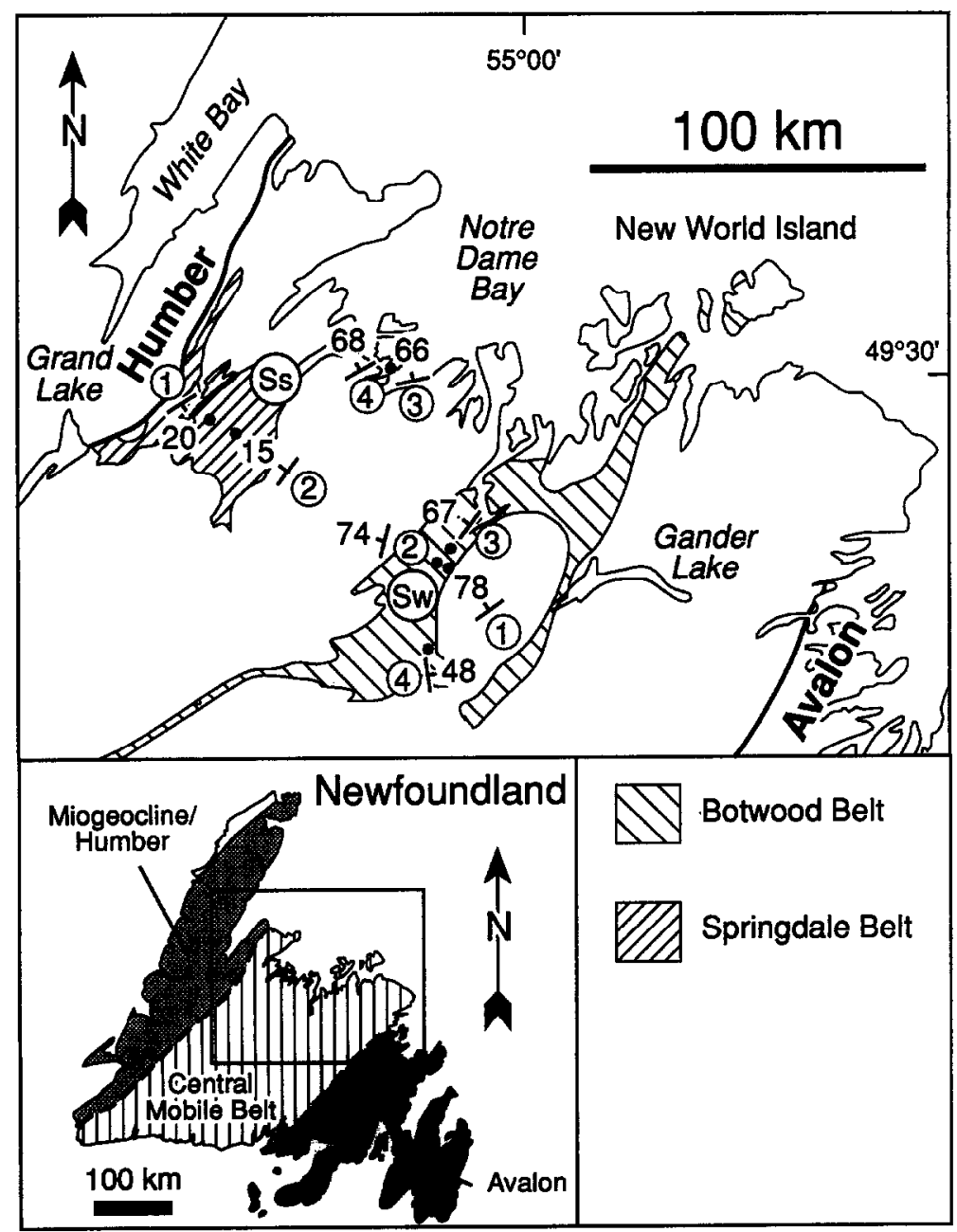

Fig. 1. Map of the north-central part of Newfoundland showing the outcrop pattern of the Silurian Botwood and Springdale rocks. Locations of Springdale (Ss) and Wigwam (Sw) sampling sites are indicated by encircled numbers with the corresponding strike and dip of bedding. Inset map shows the location of the sampling area within the tectonic domains of Newfoundland. 
the reliability of the magnetizations from the two rock types. Fold, reversal and conglomerate tests suggest that both volcanic rocks and redbeds carry primary magnetizations. Yet, because the two rock types are at least partially interbedded, the discordant nature of these apparent primary magnetizations is improbable and has suggested that one of the rock types does not accurately record the Silurian geomagnetic field. Proponents of the reliability of the redbeds have argued that the volcanics may not fully average secular variation or that structural corrections in pillow basalts are too imprecise to accurately define the paleohorizontal [8]. Such concerns do not generally hinder paleomagnetic investigations of sedimentary lithologies. However, unaveraged secular variation or inaccurate paleohorizontal seems unlikely given the dual polarity of the volcanic directions and the consistency of these directions from sites between widely spaced flows. Because of these internal consistencies and because the volcanic results yield paleolatitudes that agree with those derived from the North American APW path as well as those from paleofacies and paleoclimate data [9], we have argued that the volcanic directions more accurately record the ancient field and that the redbed directions are anomalous $[3,10,11]$.

Problems of discordant directions from similar age igneous and sedimentary rocks are not unique to Newfoundland. In other orogenic belts, like those in southern Alaska [12] or in the British Isles [13], discrepancies between directions from volcanic and clastic rocks have been explained by several mechanisms, including selective remagnetization of the sedimentary rocks, inclination error during deposition, inclination shallowing or remanence rotation due to compactional or tectonic strains, and incomplete demagnetization of one or more overprinting magnetic components. Thus, our re-examination of the paleomagnetism and magnetic susceptibility fabric of the Silurian Wigwam and Springdale Formations of Newfoundland may have important applications for other redbed studies too.

\section{Geological setting and sampling}

Both the Springdale and Wigwam redbeds consist of subareal red siliciclastic rocks deposited on top of thick sequences of epicontinental mafic and felsic volcanic rocks $[14,15]$. Contact with the underlying volcanics is conformable and occasionally the redbeds and volcanics are interbedded. Radiometric dates on the underlying volcanics and on cross-cutting dikes [16-19] as well as fossil data $[14,20]$ indicate that both the Springdale and Wigwam redbeds were deposited in the Llandoverian to Wenlockian. Radiometric results from undeformed dikes indicate that folding of the redbeds is also Silurian in age [18]. Concurrent with and preceding regional folding are episodes of both sinistral and dextral strike-slip faulting [21], that are thought to result in local rotations about vertical axes.

Paleomagnetic samples were collected from four Wigwam ( $\mathrm{Sw}$ ) and four Springdale (Ss) sites (Fig. 1). These 8 sites are sufficient for our purposes because a large number of previous studies have already produced paleomagnetic results $[1,3,7,8]$. One inch diameter cores were drilled in the field and oriented using a standard orienting device and magnetic compass. Between 6 and 18 samples were collected per site ( 94 samples in total). The sampling scheme was designed to collect from both relatively fine- and coarse-grained lithologies in order to test for possible strain or grain-size dependent effects. At sites Sw-1, Sw-2, Ss2 and Ss-4 approximately equal numbers of fine-grained and coarse-grained sandstones were collected. Sites Ss-1 and Sw-3 consist of moderate to coarse sandstones. Site Ss-3 consists of medium-grained sandstone. Site Sw-4 consists almost entirely of fine-grained sandstones with minor amounts of interbedded mudstone.

\section{Methods}

Progressive thermal demagnetization was performed on all samples using Schonstedt TSD-1 (maximum internal field of $10 \mathrm{nT}$ ) and ASC TD-48 thermal demagnetizers. Each sample was subjected to between 10 and 25 thermal demagnetization steps up to a peak temperature of $685^{\circ} \mathrm{C}$. Remanence measurements were made on a three-axis cryogenic magnetometer (2G). Both demagnetization and measurement were performed in a magnetically shielded room at the University of Michigan with a rest field of less than $200 \mathrm{nT}$. Remanence components were 
a)

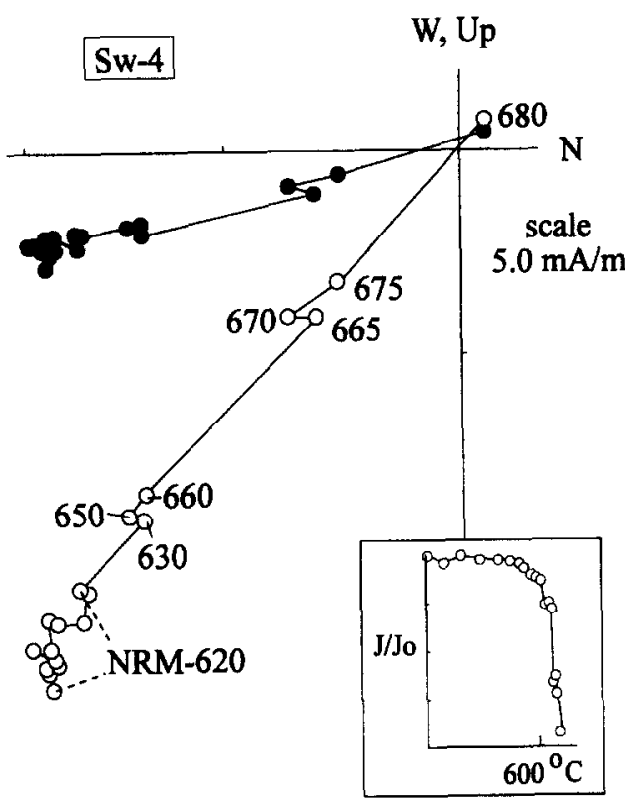

c)

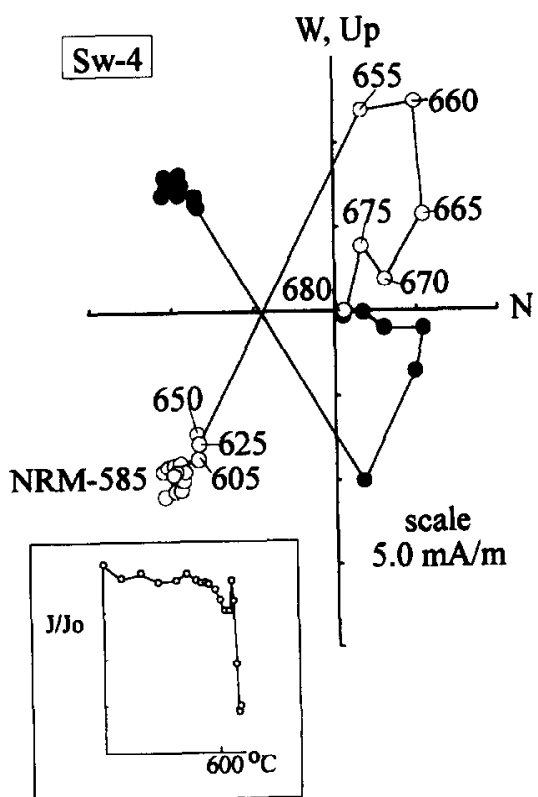

b) Ss-2

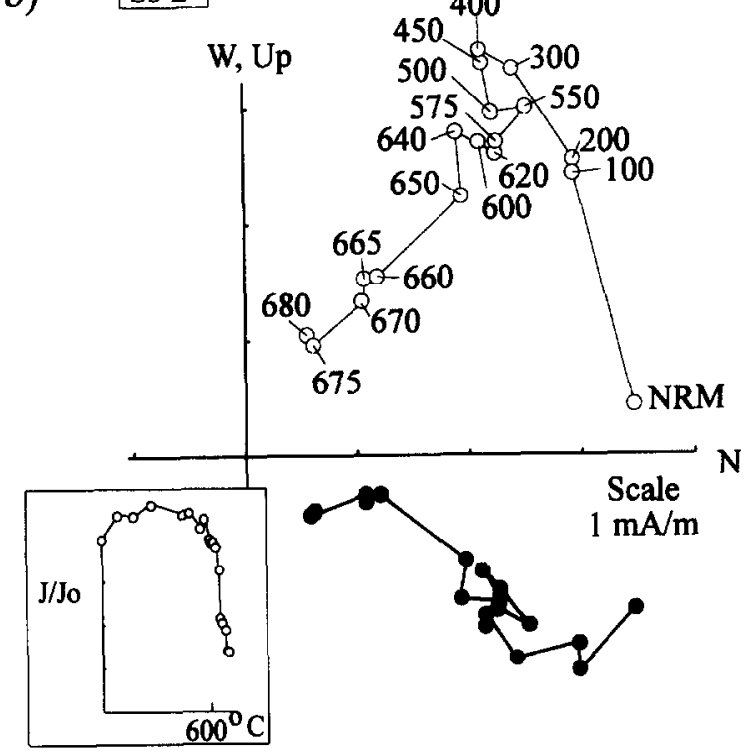

d)

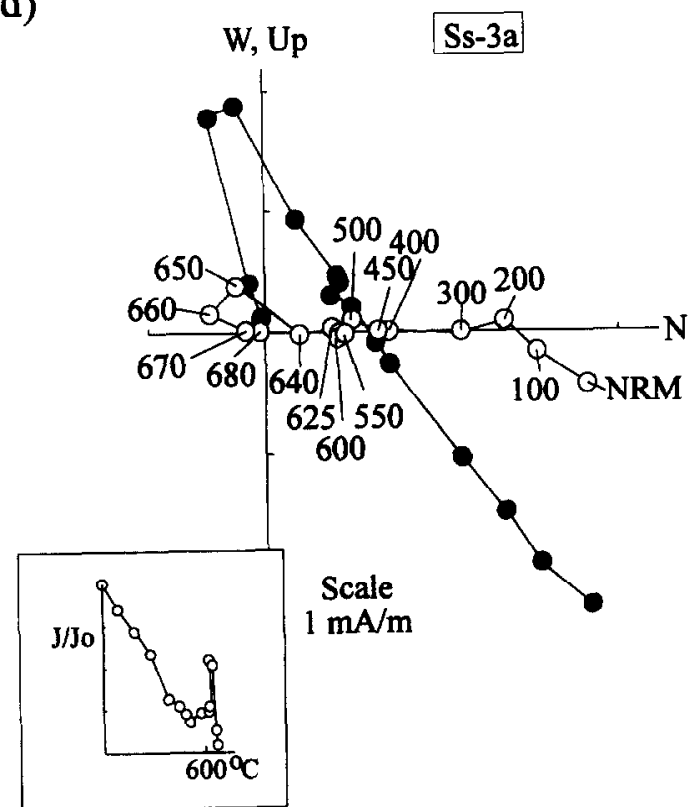

Fig 2. Orthographic projections in in-situ coordinates of vector end points during progressive thermal demagnetization [24]. Black/white Fymbols represent projections on the horizontal/vertical plane. Demagnetization steps are in degrees Celsius. Insets show the relative intensity decay of the remanent magnetization normalized to the initial intensity with temperature. (a) and (b) Type I demagnetizations. (c) and (d) Type II demagnetizations showing a dual-polarity characteristic magnetization. 
a)
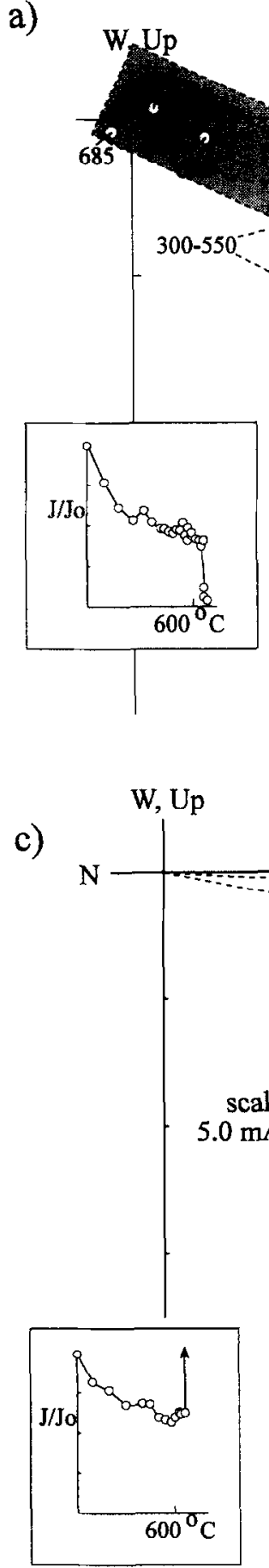

\section{Ss-2}

scale $1.0 \mathrm{~mA} / \mathrm{m}$

b)

Ss-4

W, Up
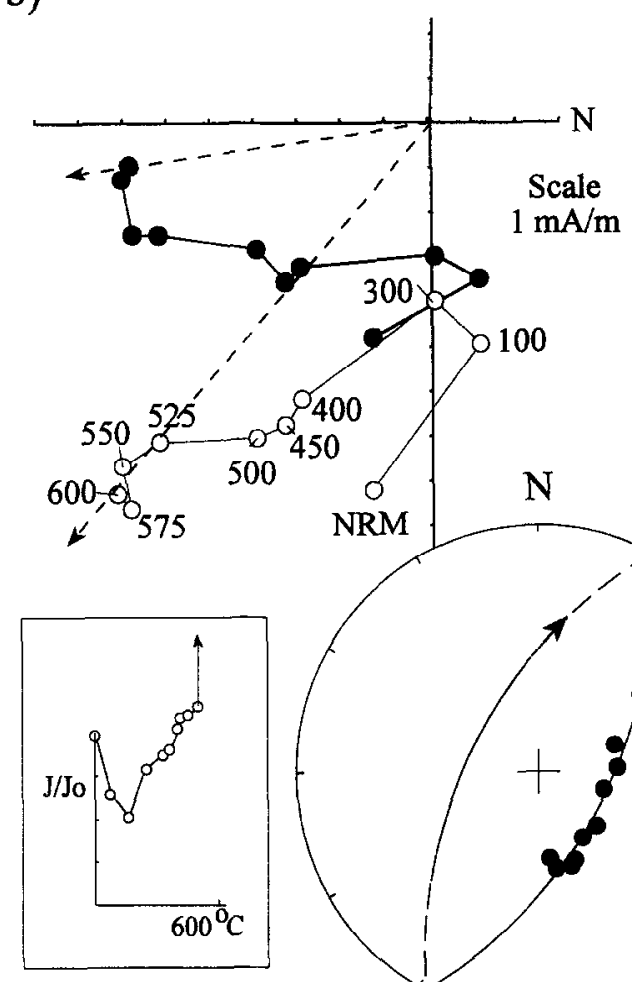

Sw-3

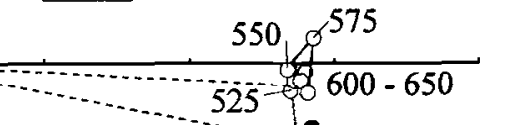

d)
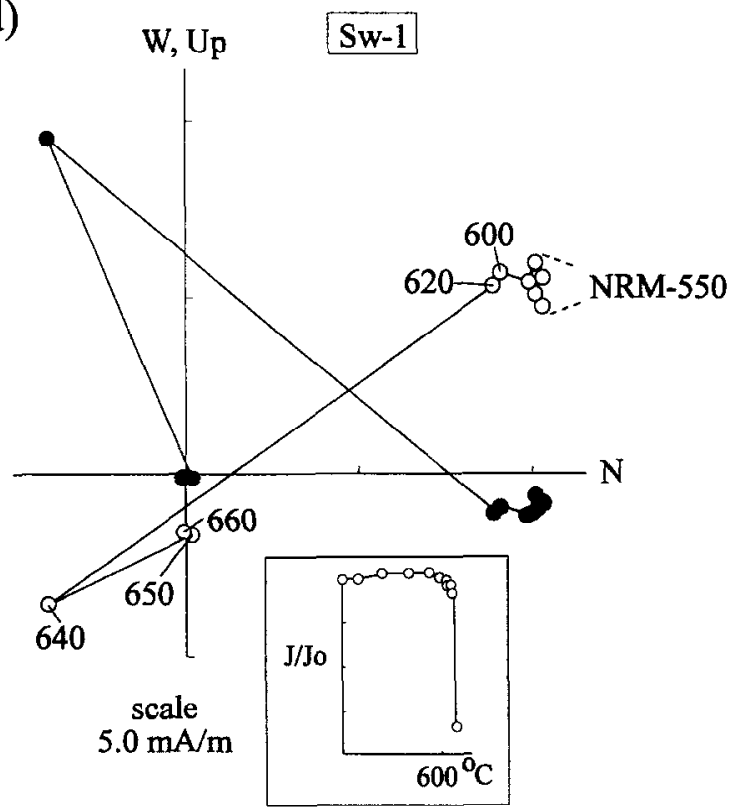

Fig. 3. Orthographic projections in in-situ coordinates of vector end points during progressive thermal demagnetization for (a) Type III, (b and c) Type IV and (d) Type V demagnetizations. Symbols are the same as in Fig. 2. In (b) and (c) the equal-angle projections show progressive change in the resultant direction during demagnetization. Black/white symbols indicate projections onto the lower/upper hemisphere of the projection. The shaded region in (a) shows the range of demagnetization steps used to define the characteristic direction. 
determined from a least-squares analysis [22,23] on linear segments of the orthogonal vector trajectories [24] or from stable end points. Mean directions and their statistical parameters were determined following the method outlined in Fisher [25].

The anisotropy of magnetic susceptibility (AMS) was measured on a KLY-2 susceptibility bridge using a twelve-position measurement procedure. The source of susceptibility was determined by comparison of the intensity of susceptibility at room temperature compared with that at $77 \mathrm{~K}[26,27]$. AMS and paleomagnetic results were also compared with optical observations made from the paleomagnetic cores and from thin sections cut from representative samples.

\section{Paleomagnetic results}

Samples from the Wigwam Formation yield a natural remanent magnetization (NRM) with moderate intensity $(5-20 \mathrm{~mA} / \mathrm{m})$ compared with slightly weaker NRM intensities in the Springdale Formation (1-10 $\mathrm{mA} / \mathrm{m})$. Thermal demagnetization produced several types of demagnetization behavior including what appear to be single-component magnetizations and several distinct patterns of overlapping, multicomponent magnetizations. For clarity we have subdivided the demagnetization behavior of the samples into five types.

\subsection{Type I: Stable demagnetization with a single, ancient characteristic component}

Type I demagnetizations are characterized by high unblocking temperatures and relatively squareshouldered intensity decay (Figs. $2 a$ and b), in which most of the magnetization vector is removed above $620^{\circ} \mathrm{C}$. In some cases, Type I behavior shows univectorial decay toward the origin with unblocking temperatures up to $680^{\circ} \mathrm{C}$ (Fig. 2a). However, several samples show initial removal of a steeply downward and northerly component that is parallel to the present Earth field in in-situ coordinates (Fig. 2b). In some samples, this present-day field (PDF) overprint is easily removed at moderate demagnetization temperatures $\left(400^{\circ} \mathrm{C}\right.$ in Fig. $\left.2 \mathrm{~b}\right)$ but in other samples this component is stable to higher unblocking temperatures in excess of $600^{\circ} \mathrm{C}$.
In geographic (in-situ) coordinates, Type I characteristic directions yield either north to east-northeast or south-southeast to south-southwest declinations with scattered shallow to moderate upward or shallow downward inclinations. Unblocking temperatures well above $585^{\circ} \mathrm{C}$ suggest that both the characteristic and PDF components are carried by hematite.

\subsection{Type II: Antipodal characteristic components}

Type II demagnetizations are characterized by two antipodal components with slightly different unblocking temperature spectra in the same sample (Figs. $2 \mathrm{c}$ and $2 \mathrm{~d}$ ). Typically, these demagnetizations show stable directions to moderately high unblocking temperatures $\left(\sim 650^{\circ} \mathrm{C}\right)$ followed by removal of an antipodal characteristic direction with discrete unblocking temperatures between 650 and $685^{\circ} \mathrm{C}$ (Fig. 2c). Occasionally, however, the lower temperature component is removed over a broad range of unblocking temperatures followed by unblocking of an antipodal characteristic magnetization with discrete unblocking temperatures (Fig. 2d). Type II directions are similar to Type $I$, and both types are characteristic of finer grained samples, as we discuss below.

\subsection{Type III: Multi-component demagnetization}

Type III behavior is characterized by complex multi-component demagnetizations (Fig. $3 a$ ) and is typical of the coarse-grained sandstones. Demagnetizations are noisy and linear components typically have large mean angular deviations (MAD) greater than $20^{\circ}$. Characteristic directions (when they can be defined) are scattered, although site Ss-2 produced a set of consistent directions with northerly declinations and shallow upward and downward inclinations in tilt-corrected coordinates. Comparison of these directions with Type I and II directions from the fine-grained samples of this site show that the directions from the coarse-grained samples are significantly shallower (Fig. 4).

\subsection{Type IV: Reactive demagnetization}

Type IV behavior is characterized by the growth of new magnetic minerals during thermal demagneti- 
Table 1

Paleomagnetic results from the Springdale and Wigwam Formations

\begin{tabular}{|c|c|c|c|c|c|c|c|}
\hline Site & $\begin{array}{l}\text { Bedding } \\
\mathrm{DD} / \mathrm{D}\end{array}$ & $N / n$ & $\begin{array}{l}\text { In Situ } \\
\text { Dec/Inc }\end{array}$ & $\begin{array}{l}\text { Tilt Corrected } \\
\text { Dec/Inc }\end{array}$ & $\begin{array}{c}\text { Strike } \\
\text { Corrected } \\
\text { Dec/Inc }\end{array}$ & $k$ & $\alpha_{95}$ \\
\hline \multicolumn{8}{|c|}{ Type $I, I, \&$ V Demagnetization } \\
\hline Sw-1 & $315 / 78$ & $18 / 12$ & $187.5 / 10.7$ & $229.2 / 38.6$ & $229.2 / 38.6$ & 30.5 & 08.0 \\
\hline Sw-2 & $288 / 74$ & $13 / 9$ & $161.1 / 06.2$ & $193.6 / 37.1$ & $220.6 / 37.1$ & 12.6 & 15.1 \\
\hline Sw-3 & $307 / 67$ & $12 / 10$ & $007.7 / 14.5$ & $010.8 /-19.8$ & $023.8 /-19.8$ & 21.3 & 10.7 \\
\hline Sw-4 & $086 / 48$ & $13 / 10$ & $191.3 / 44.2$ & $146.7 / 37.3$ & 195.7/37.3 & 13.8 & 13.5 \\
\hline Ss-1 & $150 / 20$ & $12 / 1$ & $(227.2 / 32.2)$ & $(216.5 / 25.9)$ & $(210.5 / 25.9)$ &.-- &.- \\
\hline Ss-2 & $305 / 15$ & $12 / 6$ & $037.3 /-48.7$ & $053.5 /-46.0$ & $063.5 /-46.0$ & 27.7 & 13.0 \\
\hline Ss-3 & $356 / 66$ & $6 / 4$ & $056.8 / 01.7$ & $071.5 /-25.7$ & $030.5 /-25.7$ & 21.6 & 20.2 \\
\hline Ss-4 & $330 / 68$ & $8 / 4$ & $017.3 /-18.7$ & $064.7 /-45.7$ & $049.7 /-45.7$ & 91.1 & 09.7 \\
\hline Mean * & & $8 / 7$ & $195.6 / 17.1$ & & & 06.3 & 26.0 \\
\hline Mean $†$ & & $8 / 7$ & & $212.9 / 41.1$ & & 07.1 & 24.4 \\
\hline Mean $\ddagger$ & & $8 / 7$ & & & $217.2 / 36.7$ & 24.5 & 12.4 \\
\hline \multicolumn{8}{|c|}{ Type III Demagnetization } \\
\hline Ss-2 & $305 / 15$ & $12 / 6$ & $014.0 /-0.0$ & $016.5 /-12.6$ & $026.5 /-12.6$ & 09.9 & 22.3 \\
\hline \multicolumn{8}{|c|}{ Type I \& II Demagnetization only } \\
\hline Sw-1 & $315 / 78$ & $18 / 5$ & $193.9 / 16.3$ & $236.8 / 32.9$ & $236.8 / 32.9$ & 24.9 & 15.6 \\
\hline Sw-2 & $288 / 74$ & $13 / 6$ & $155.5 /-1.2$ & $182.3 / 40.1$ & $209.3 / 40.1$ & 12.6 & 19.6 \\
\hline Sw-3 & $307 / 67$ & $12 / 0$ & $-.-1-.$. & $-.-1,-$ &.$--/-.-$ &.-- &.- \\
\hline Sw-4 & $086 / 48$ & $13 / 6$ & $193.6 / 48.7$ & $142.0 / 40.6$ & $191.0 / 40.6$ & 17.3 & 16.6 \\
\hline Ss-1 & $150 / 20$ & $12 / 1$ & $(227.2 / 32.2)$ & $(216.5 / 25.9)$ & $(201.5 / 25.9)$ & $\ldots$ & $\because-$ \\
\hline Ss-2 & $305 / 15$ & $12 / 6$ & $037.3 /-48.7$ & $053.5 /-46.0$ & $063.5 /-46.0$ & 27.7 & 13.0 \\
\hline Ss-3 & $356 / 66$ & $6 / 4$ & $056.8 / 01.7$ & $071.5 /-25.7$ & $030.5 /-25.7$ & 21.6 & 20.2 \\
\hline Ss-4 & $330 / 68$ & $8 / 4$ & $017.3 /-18.7$ & $064.7 /-45.7$ & $049.7 /-45.7$ & 91.1 & 09.7 \\
\hline Mean * & & $8 / 6$ & $197.9 / 23.6$ & & & 05.8 & 30.5 \\
\hline Mean $†$ & & $8 / 6$ & & $218.3 / 42.3$ & & 07.1 & 24.3 \\
\hline Mean $\ddagger$ & & $8 / 6$ & & & $219.2 / 39.9$ & 23.1 & 14.2 \\
\hline \multicolumn{8}{|c|}{ Type V Demagnetization only } \\
\hline Sw-1 & $315 / 78$ & $18 / 7$ & $183.2 / 6.6$ & $223.1 / 42.2$ & $223.1 / 42.2$ & 53.4 & 08.3 \\
\hline$S w-2$ & $288 / 74$ & $13 / 3$ & $171.7 / 20.1$ & $212.4 / 29.7$ & $239.4 / 29.7$ & 96.8 & 12.6 \\
\hline Sw-3 & $307 / 67$ & $12 / 10$ & $007.7 / 14.5$ & $010.8 /-19.8$ & $023.8 /-19.8$ & 21.3 & 10.7 \\
\hline $\mathrm{Sw}-4$ & $086 / 48$ & $13 / 4$ & $168.8 / 27.8$ & $150.4 / 13.3$ & $199.4 / 13.3$ & 14.8 & 24.7 \\
\hline Mean * & & $8 / 4$ & $177.5 / 10.2$ & & & 15.7 & 23.9 \\
\hline Mean † & & $8 / 4$ & & $191.9 / 29.1$ & & 06.9 & 37.7 \\
\hline Mean $\ddagger$ & & $8 / 4$ & & & $213.5 / 27.3$ & 13.9 & 25.5 \\
\hline
\end{tabular}

Site numbers ( $\mathrm{Sw}$ for Wigwam Formation and Ss for Springdale Formation) refer to the site locations shown in Fig. 1. $D D$ and $D$ are the dip direction and dip of bedding. $N$ and $n$ are the number of samples demagnetized and the number used in the analysis. Dec and $I n c$ are the declination and inclination of the site-mean directions. $k$ and $\alpha_{95}$ are the precision parameter and the $95 \%$ confidence region around the mean directions as defined by Fisher [25]. Site directions converted to a common polarity when the mean directions were computed. The directions of site Ss-1 are placed in parentheses and have not been included in the means." In-situ coordinates; $\dagger$ stratigraphic coordinates; ¥ bedding strike correction in which directions are rotated about a vertical axis so that bedding strikes are all northeast-southwest. 
zation (Figs. 3b and 3c). In these samples the intensity of magnetization increases exponentially after heating, usually at oven temperatures above $600^{\circ} \mathrm{C}$. This sudden increase in intensity then masks isolation of the characteristic magnetization. In some samples this sudden intensity increase occurs during unblocking of what appears to be antipodal components (Fig. 3b, in which a northeast and upward direction was removed from a southerly and downward direction). In other samples, the intensity increase occurs during or after removal of a strong PDF component (Fig. 3c). No characteristic directions were obtained from Type IV behavior.

\subsection{Type V: End points}

Type V demagnetizations appear stable over a broad range of unblocking temperatures between 20

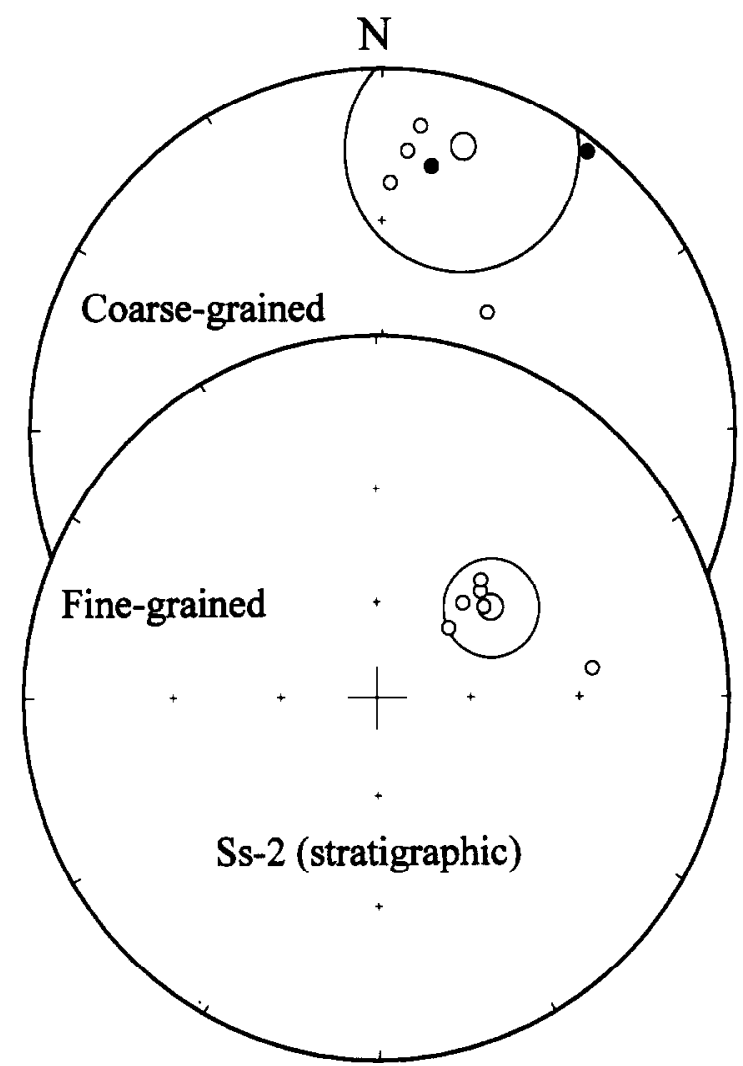

Fig. 4. Equal-angle projection showing the sample (small circles) and mean directions (larger circles) and associated $\alpha_{95}$ 's (largest circles) for the coarse-grained and fine-grained samples of site Ss-2. Symbols are the same as in Fig. 3. and $620^{\circ} \mathrm{C}$ (Fig. 3d). Unblocking occurs over a narrow temperature range above $620^{\circ} \mathrm{C}$ followed by the removal of what is either a component or possibly an antipodal component. As such, these demagnetizations may represent either a Type II direction in which the antipodal direction is not clearly resolved or a Type IV magnetization in which the magnetizations become spurious at high unblocking temperatures. Because these directions do not decay linearly toward the origin, stable end points were used to define the characteristic directions. Type $\mathrm{V}$ results are roughly similar to Type I and II results with north and upward or south and downward directions, although there appear to be important differences between the Type $V$ and the Type I and II results, as we discuss below.

\subsection{Mean directions and fold test results}

For our initial computation of mean directions we have use only Type I, II and V results (Table 1). The complex patterns of Type III and IV demagnetizations make it likely that single-component, characteristic magnetizations are not clearly defined in these samples, which may also be true for the Type III directions of site Ss-2 (Table 1). Mean directions were calculated for 7 of the 8 sites (55 samples). Site Ss-1 had only one reliable direction and, although this sample direction is consistent with our other results, it was not included in the calculation of the final mean directions. In geographic coordinates, site means directions yield either southerly declinations with shallow to moderately downward inclinations or north to northeast declinations and moderately upward to shallow downward inclinations (Fig. 5a). Upon tilt correction, the declinations remain scattered but the inclinations appear to cluster at either intermediate upward or downward angles (Fig. 5b). Because we suspect significant vertical axis rotations associated with strike-slip faulting across Newfoundland, we use an inclination-only tilt test to quantify the paleomagnetic fold test $[27,28]$. Results from this test show a seven-fold increase in $k$, indicating that the magnetization is pre-folding (Fig. 5d). Correcting for bedding strike by rotating the site-mean directions about a vertical axis until all bedding strikes coincide along a northeast-southwest direction also indicates that this magnetization is pre-tectonic in 
age (Fig. Sc). Although the overall mean declination is unconstrained in this test because the reference strike was arbitrarily taken as northeast-southwest, the resulting distribution of site mean directions shows a moderately well clustered, two-polarity magnetization. The mean inclination for all Type I, II and $\mathrm{V}$ directions of $37^{\circ} \pm 12^{\circ}$ corresponds to a paleolatitude of $21^{\circ}(\mathrm{S}) \pm 8^{\circ}$. We interpret the gener- ally north and up/south and down directions as normal/reverse polarity southern hemisphere magnetizations, which yields the southern (negative) hemisphere paleolatitude. Because Type $V$ demagnetizations did not decay to the origin, it is possible that these end-point directions are not single component but composite magnetizations with overlapping thermal unblocking spectra. Separation of the lines a)

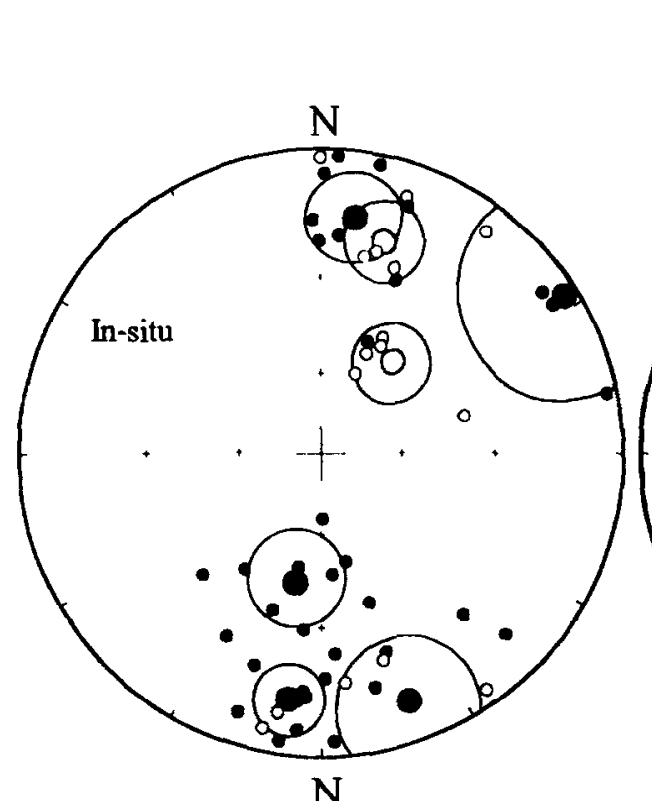

c)

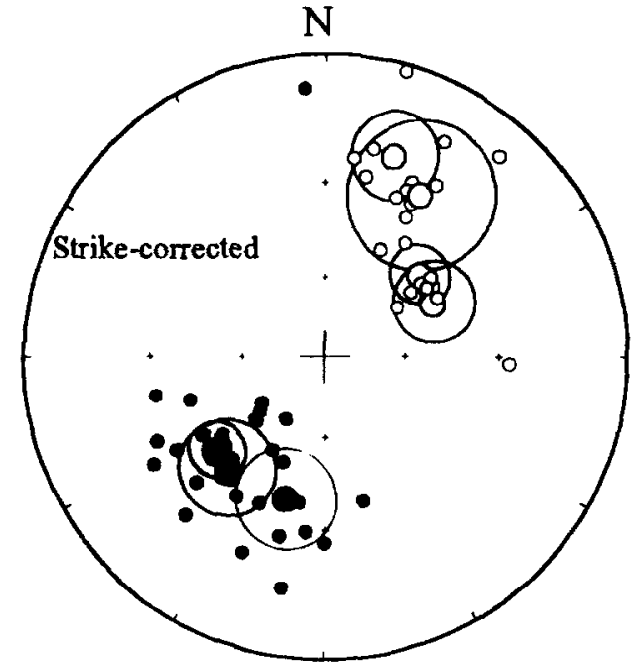

b)<smiles>[Te][Te]</smiles><smiles>[Te][Te][Te]</smiles>

d)

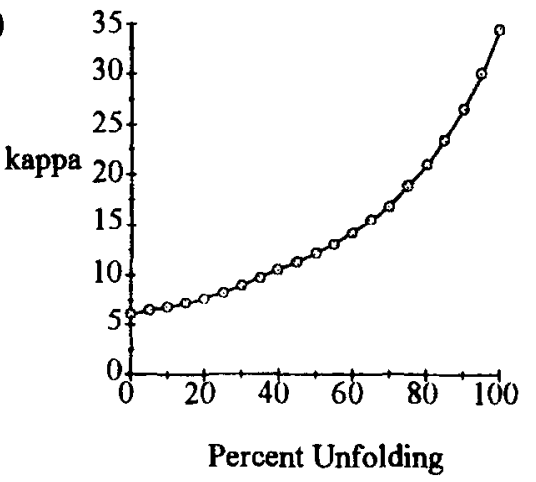

Fig. 5. Equal-angle projections showing the sample and site means in in-situ (a), tilt-corrected (b) and strike-corrected (c) coordinates. Symbols are the same as in Figs. 3 and 4. Bedding strikes are indicated in (b) with their corresponding site names. (d) The Fisher [25] precision parameter kappa $(k)$, based on inclination-only statistics, plotted as a function of percent unfolding. 
and end points (24 Type $V$ directions and 32 Type I or II directions) shows that although not statistically distinct the Type $\mathrm{V}$ directions are shallower and have

a)
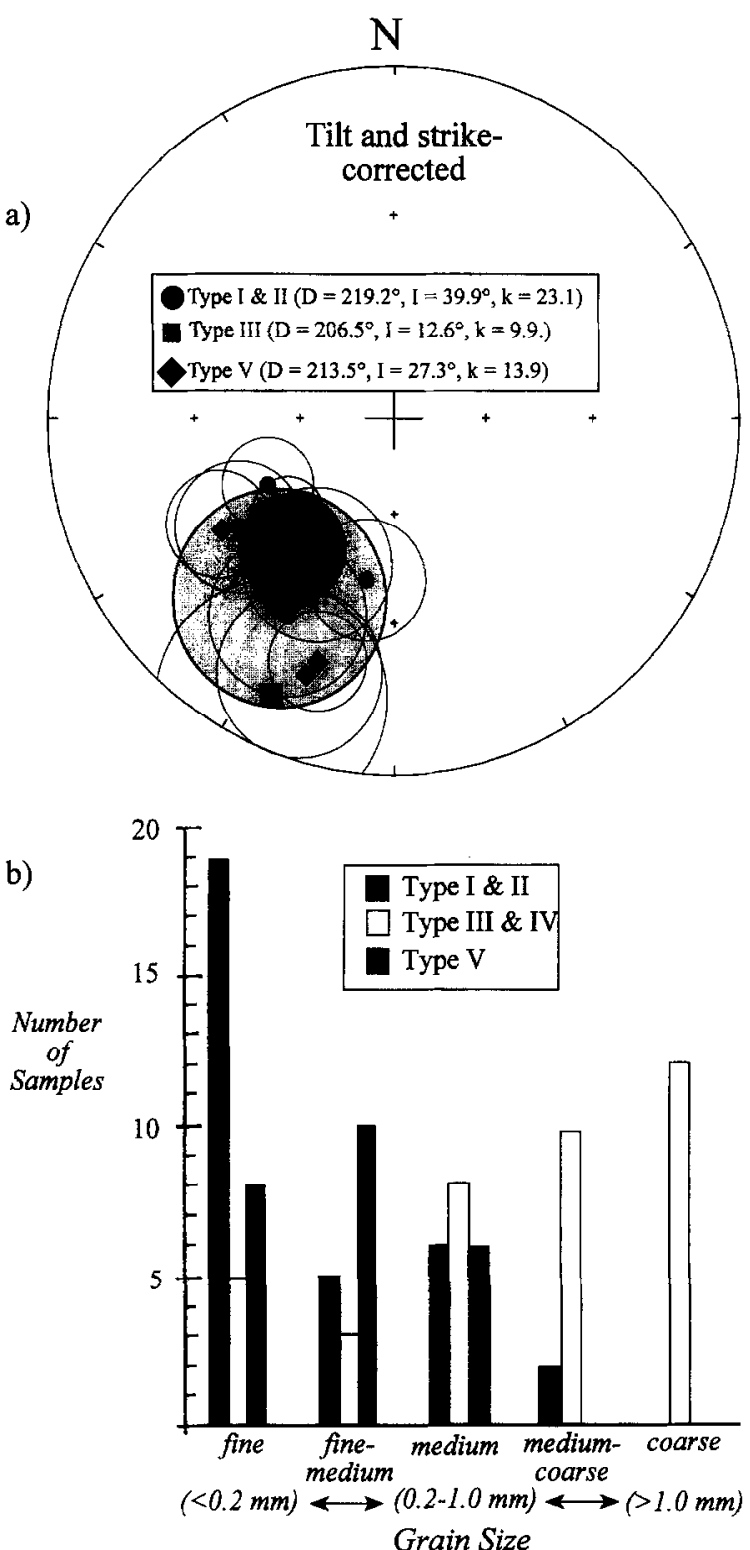

Fig. 6. (a) Equal-angle projection showing the site-mean directions and overall mean directions with shaded cones of $95 \%$ confidence using either all Type I and II results (shaded circles) or the Type $\mathrm{V}$ results (diamonds). Type III results from Ss-2 are shown as a square. All directions converted to reverse polarity. Symbols are the same as in Figs. 3 and 4. (b) Histogram of the number of samples showing a given demagnetization behavior as a function of grain size of the sample. a larger scatter than the Type I and II directions (Table 1 and Fig. 6a). Based solely on the more reliable Type I and II directions, the mean inclination of $40^{\circ} \pm 14^{\circ}$ corresponds to a paleolatitude of $23^{\circ}(\mathrm{S}) \pm 9^{\circ}$. The type of demagnetization behavior depends in large part on the grain size of the samples (Fig. 6b). The most reliable directions (Type I and II) are primarily found in the finest grained sandstones. Type $\mathrm{V}$ directions, which yield slightly shallower directions with larger scatter, are found in the fine- to medium-grained sandstones. In contrast, Type III and IV directions, which produced the very shallow mean direction at site Ss-2, are generally found in the medium- to coarse-grained samples.

\section{AMS results}

Susceptibility measurements show distinctive patterns between the redbeds of the two formations. Bulk susceptibility values for the Springdale samples range between $9.0 \times 10^{-5}$ (SI) and $4.5 \times 10^{-4}$ (SI). Susceptibility values for the Wigwam samples are an order of magnitude stronger and range between 9.5 $\times 10^{-4}$ (SI) and $2.5 \times 10^{-3}$ (SI). The ratio of the bulk susceptibility at room temperature to that at 77 $\mathrm{K}$ is between 1.3 and 1.7 for the Wigwam samples and between 3.2 and 3.5 for the Springdale samples. These results indicate that the susceptibility is primarily carried by a ferromagnetic phase (hematite) in the Wigwam Formation and by a paramagnetic mineral phase (chlorite) in the Springdale Formation. Optical observations from oriented thin sections support these observations. The Wigwam samples show framework grains of quartz, feldspar and mafic minerals surrounded by a hematite cement. The Springdale samples show quartz and feldspar with both crenulated detrital and secondary phyllosilicates. The magnetic fabrics recorded by the AMS measurements also show distinct differences between the two formations. In the Wigwam samples, AMS results reveal bedding-controlled (sedimentary) fabrics characterized by weakly oblate susceptibility ellipsoids with minimum axes perpendicular to bedding (Figs. 7a-d and i). In contrast, AMS results from the Springdale samples show what appears to be a composite tectonic-bedding fabric characterized by both prolate and oblate susceptibility ellipsoids with mini- 
mum axes subperpendicular to cleavage and maximum axes near the intersection of bedding and the foliation plane of the AMS ellipsoid (Figs. 7e-h and j). Unlike the remanence data, we find no relationship between AMS fabrics and the grain size of the samples.

\section{Discussion}

The characteristic directions from the Springdale and Wigwam redbeds yield a pre-folding and pre-rotational magnetization with antipodal directions. Because deformation occurred soon after deposition in the early Silurian, this magnetization is most likely primary. The paleolatitude of $23^{\circ}(\mathbf{S}) \pm 9^{\circ}$ is similar to that predicted for Newfoundland from the North American APW path (Fig. 8) and to paleolatitudinal estimates from coeval volcanic rocks [1-3], but is significantly different from previous paleolatitudinal estimates derived from these same redbeds $[3,6-8]$.

The range of paleolatitudinal estimates from the redbed studies compared with the consistent results from the volcanic studies illustrates the systematic bias of the previous redbed results toward anomalously low paleolatitudes (Fig. 8). This bias was first pointed out by Potts et al [3] for the Springdale redbeds. Our observations of the relationship between remanence and grain size indicate that this bias is most pronounced in the coarse-grained sand- a)

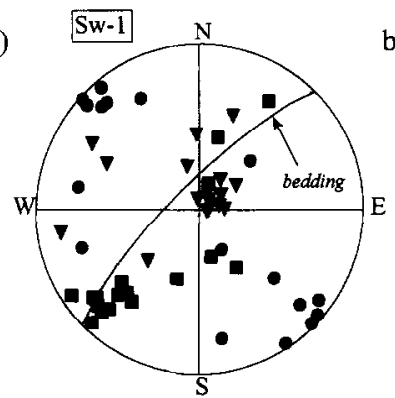

e) $\mathrm{ss}-1$
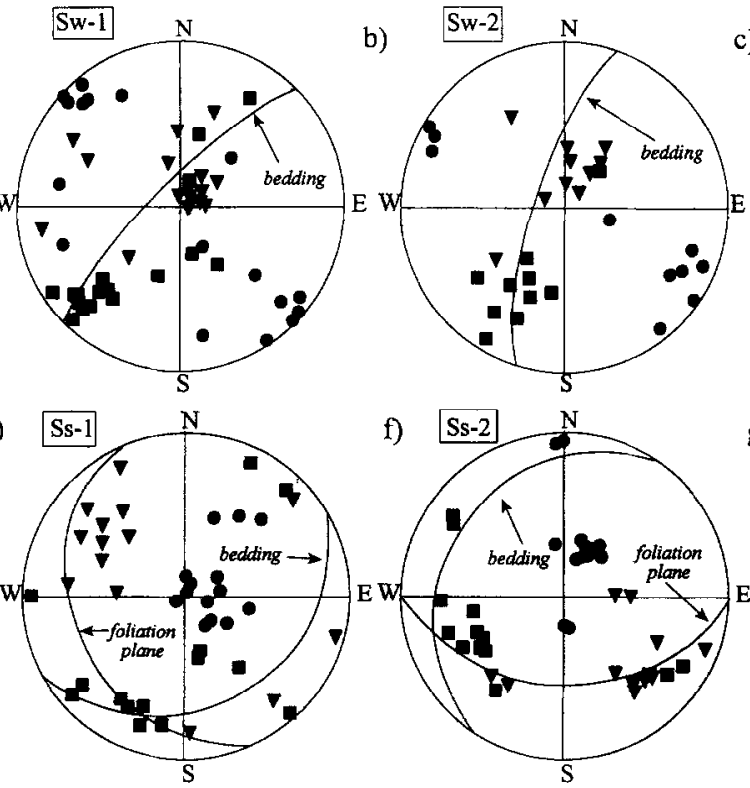

f) $\lfloor\mathrm{ss}-2 \mid \mathrm{N} \quad \mathrm{g}$

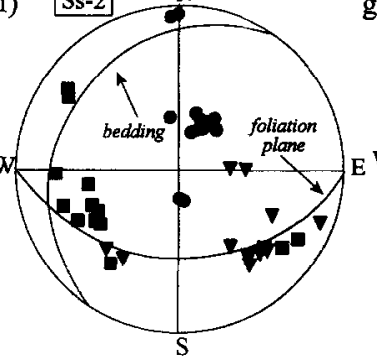

c)

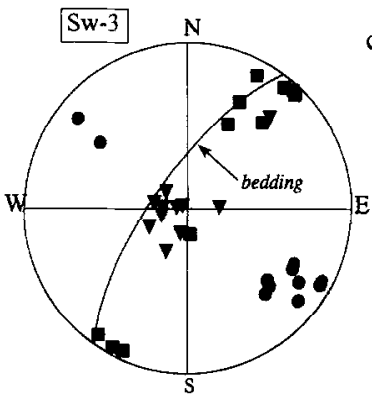

g)

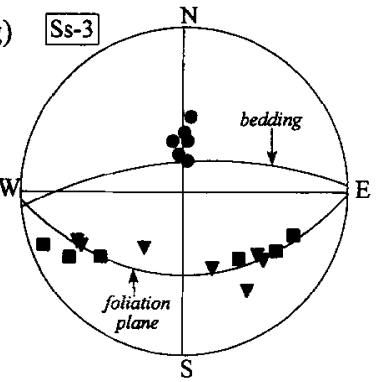

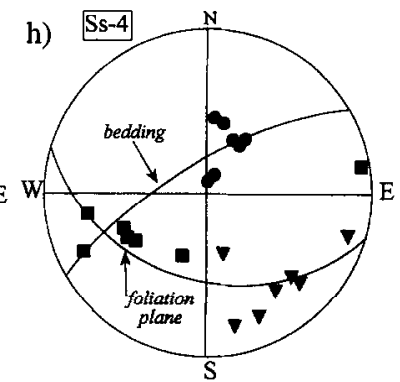

d)

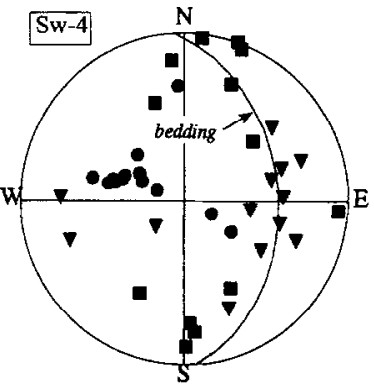

h)
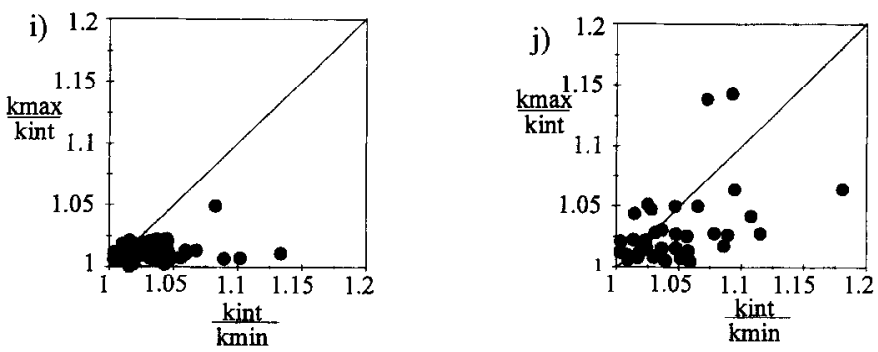

Fig. 7. (a-h) Lower hemisphere, equal-area projections showing the orientation of principle axes of the AMS ellipsoids. Squares are the maximum axes; triangles are the intermediate axes; shaded circles are the minimum axes. ( $i$ and $j$ ) Modified Flinn diagrams plotting the ratios of the lengths of principle axes. 
stones and that only the finest grained sandstones yield reliable Silurian magnetizations for Newfoundland.

\subsection{Demagnetization effects}

The most likely explanation for the observed grain-size effect is incomplete isolation of a primary characteristic direction in the coarser grained samples. Based on our detailed analyses of the demagnetization characteristics, it appears that incomplete demagnetization of overlapping components may, at least in part, explain the anomalous redbed directions from previous studies. We see evidence for contamination due to a strong present-day field component and mixing of normal and reversed polarity compo- nents, whose composite directions are generally shallower than a single-component characteristic direction defined by a linear decay toward the origin. This effect is most evident in the comparison of the Type I and II results derived from lines compared with Type $\mathrm{V}$ directions derived from stable end points or Type III directions derived from the complex demagnetization trajectories (Figs. 4 and 6a).

Previous results from these redbeds $[3,6-8]$ included directions from both line and end-point analyses. As a result, cones of $95 \%$ confidence around the site mean directions were large, with an average value of $18^{\circ}$ and some over $25^{\circ}$. In contrast, and even with fewer samples per site, the $95 \%$ cones of confidence from our analyses average around $14^{\circ}$. This improvement in precision highlights the impor-

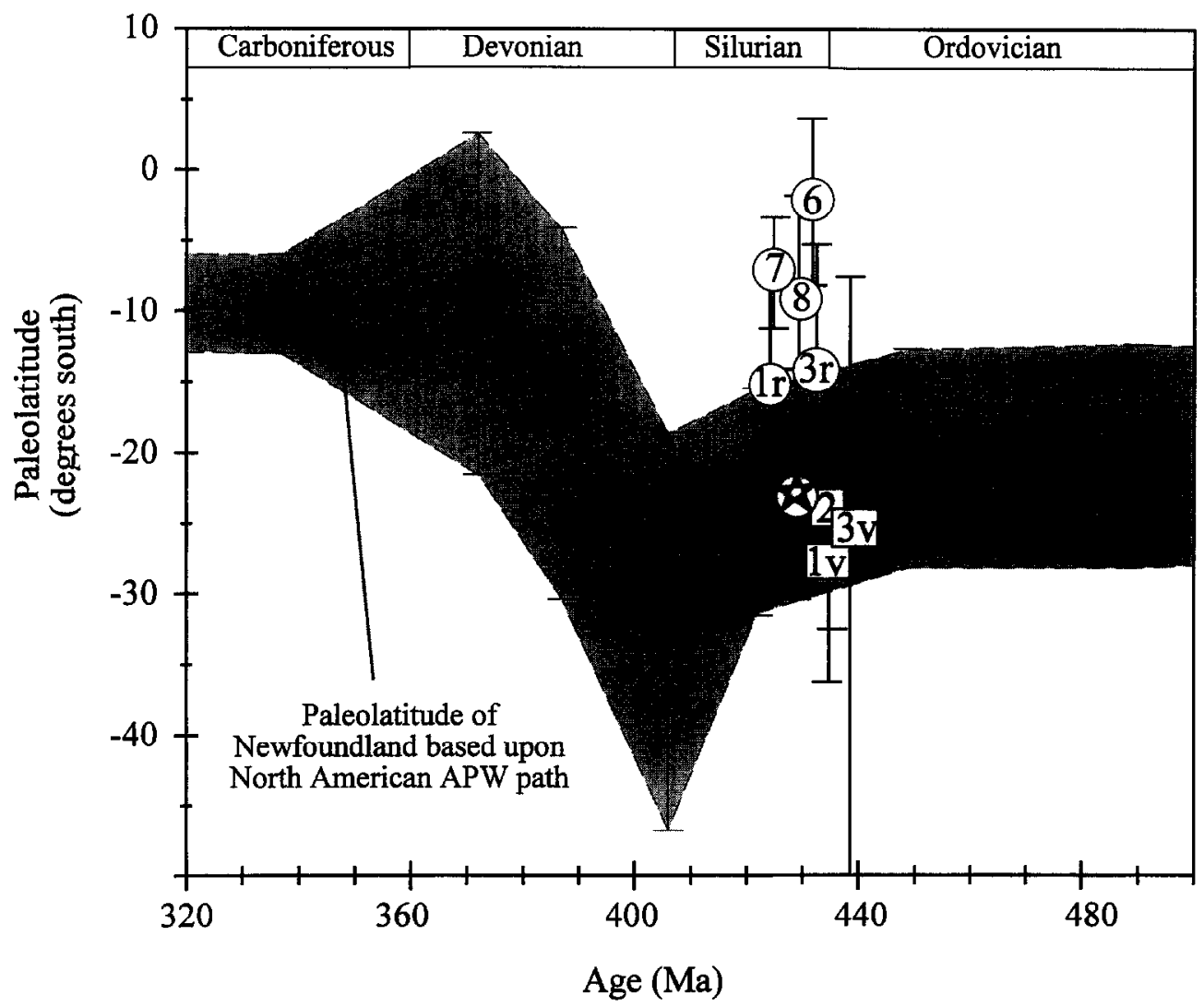

Fig. 8. Paleolatitude estimates for Newfoundland from redbed studies (circles) and volcanic studies (squares). The paleolatitude reference curve for Newfoundland is based on the mean poles of Van der Voo [4]. The error region was calculated from the $A_{95}$ of the mean poles. Numbers in the symbols refer to the numbered citations in the reference list ( $r$ for redbed result and $v$ for volcanic result). The star is the paleolatitude from this study. 
tance of using only the highest quality demagnetization data (those showing well-defined linear decay toward the origin) in the computation of the characteristic site-mean directions.

\subsection{Inclination error}

Inclination error associated with deposition of the coarse-grained lithologies may also have contributed to the observed shallow inclinations. As it was originally defined, 'inclination error' was used to describe the shallower than expected inclinations of a depositional remanent magnetization (DRM) due to settling of platy or elongate magnetic grains within bedding $[29,30]$. More recent work has extended the meaning to include post-depositional processes such as compaction. In this discussion, we adhere to the original definition.

King's [30] model quantified inclination error according to the equation:

$\tan \left(I_{\mathrm{o}}\right)=f \cdot \tan \left(I_{\mathrm{h}}\right)$

where $I_{\mathrm{o}}$ is the resulting inclination, $I_{\mathrm{b}}$ is the inclination of the ambient field, and $f$ is fraction of spheres to total grains (plates and spheres). Experimental and natural results on hematite-bearing fluvial sandstones confirm inclination errors according to this model and give values of $f$ between 0.40 and 0.55 [31,32].

As is the case for many redbeds, there is no direct evidence in the Springdale and Wigwam rocks to indicate whether the characteristic remanence is a DRM or a chemical remanent magnetization (CRM) that was acquired during diagenesis, within a few million years after deposition. Based on optical observations from thin sections, Hodych and Buchan [8] noted what they considered to be detrital hematite grains in the Wigwam Formation. However, distinguishing CRM from DRM is problematic given the similarity of CRM- and DRM-carrying hematite and the inability to detect which are the important remanence-carrying grains solely from optical observations. One possibility is that there are elements of both DRM and CRM in these rocks, perhaps to the extent that the dual polarity characteristic magnetization (Type II) represents a DRM overprinted with a slightly younger CRM of opposite polarity.

Substituting the previously reported redbed incli- nations $[1,3,6-8]$ for $I_{\mathrm{o}}$ and using $40^{\circ}$, based on the North American APW path [4], for $I_{h}$, Eq. (1) yields $f$ values of $0.66,0.43,0.09,0.37$ and 0.31 respectively. In a similar fashion, the $f$ ratio determined from the mean directions of the coarse sandstones $\left(I_{\mathrm{o}}\right)$ and fine-grained mudstones $\left(I_{\mathrm{b}}\right)$ samples at site Ss-2 is 0.21 . Except for the low $f$ ratio from site Ss- 2 and the very low $f$ ratio from the King George IV Lake [6], these $f$ values are reasonably consistent with those from the experimental results [31,32]. The slightly lower values for $f$ for site Ss-2 and King George IV Lake possibly indicate a greater fraction of platy hematite in these rocks. Based on these results, we suggest that inclination error may at least partially explain the shallow inclinations previously observed in these rocks. As expected, the effect is most pronounced in the coarsest grained samples because these rocks were deposited in relatively higher energy environments. Both contamination by overprints and inclination error produce similar deviations of remanent directions in the coarser grained rocks, and therefore, the two effects cannot be distinguished from each other from the directional data alone. Moreover, because only the fraction of remanence-carrying hematite and not the entire population of ferromagnetic and paramagnetic grains may be affected, AMS, and by analogy anisotropy of remanence [11], may prove ineffective in detecting inclination error.

\subsection{Strain effects}

Previous studies of redbeds have shown that both compaction and internal strains associated with deformation can cause a significant deflection of the remanent magnetization [33]. In both cases the degree of remanence rotation appears to be controlled in part by the grain size of the rock's matrix grains, simply because the finer grained rocks are less competent and tend to absorb a greater proportion of internal deformation. Unlike inclination error associated with deposition where the bulk magnetic fabric may be unrelated to the magnetic fraction that carries the stable remanence [10], compaction or other strain-related effects should show a distinct relationship between the development of the magnetic fabric and the orientation of remanence [33]. 
We do not find any evidence that post-depositional strain, either compaction or tectonic, has significantly affected the magnetization in these rocks. In this study, the steepest directions are found in the finest grained samples, opposite to what is predicted for the accumulation of internal strain in fine- and coarse-grained rocks. Moreover, the AMS results suggest that the Wigwam samples preserve a sedimentary-related fabric whereas the Springdale samples show the development of a tectonic fabric. Yet, despite these differences in fabric development, the grain-size effects on remanence appear to be similar in both formations. The progressive development of these fabrics does not appear to have affected the orientation of remanence, and we observe no correlation between remanence directions and the degree of magnetic anisotropy.

\section{Conclusions}

Detailed thermal demagnetization of the Silurian Springdale and Wigwam redbeds of Newfoundland yield a pre-folding and pre-rotational magnetization that appears to contain elements of both a depositional (DRM) and diagenetic chemical (CRM) remanent magnetization. Unlike previously reported results for these rocks, which place Newfoundland near the paleoequator in the Silurian, our analyses yield a paleolatitude for Newfoundland of $23^{\circ}(S) \pm$ $9^{\circ}$, consistent with that from coeval volcanic rocks and with the paleolatitude predicted for Newfoundland based on the reference North American APW path. Our results also suggest significant vertical axis rotations in the region after remanence acquisition.

Based on our observations, the most likely explanations for the anomalous redbed directions previously reported from these rocks are the incorporation of incompletely isolated characteristic directions into the overall mean and possible inclination error related to the acquisition of a DRM. We do not find evidence for significant deflection of remanence due to compaction or subsequent tectonic strains. These results suggest that, in these redbeds, the finer grained sandstones are the more accurate recorders of the ancient geomagnetic field.

\section{Acknowledgements}

Field work for this project was carried out by Sean Todaro and Don Cederquist and was partially supported by the Scott Turner Fund of the University of Michigan. Laboratory work was supported by the National Science Foundation (grants EAR 9118021 and EAR 9217986). Ange Lessard was supported through the University of Michigan's Undergraduate Research Opportunity Program (UROP). We thank Jim Channell, Ken Buchan and an anonymous reviewer for their comments, which improved the quality of this paper. [CL]

\section{References}

[1] P.L. Lapointe, Paleomagnetism and orogenic history of the Botwood Group and Mount Peyton Batholith, Central Mobile Belt, Newfoundland, Can. J. Earth Sci. 16, 866-876, 1979.

[2] J.E. Gales, B.A. van der Pluijm and R. Van der Voo, Paleomagnetism of the Lawrenceton Formation volcanic rocks, Silurian Botwood Group, Change Island, Newfoundland, Can. J. Earth Sci. 26, 296-304, 1989.

[3] S.S. Potts, B.A. van der Pluijm and R. Van der Voo, Discordant Silurian paleolatitudes for central Newfoundland: New paleomagnetic evidence from the Springdale Group, Earth Planet. Sci. Lett. 120, 1-12, 1994.

[4] R. Van der Voo, Paleomagnetism of the Atlantic, Tethys and Iapetus Oceans, Cambridge University Press, New York, 1993.

[5] B.A. van der Pluijm, R.E. Johnson and R. Van der Voo, Early Paleozoic paleogeography and accretionary history of the Newfoundland Appalachians, Geology 18, 898-901, 1990.

[6] K.L. Buchan and J.P. Hodych, Early Silurian paleopole for redbeds and volcanics of the King George IV Lake area, Newfoundland, Can. J. Earth Sci. 26, 1904-1917, 1989.

[7] K.L. Buchan and J.P. Hodych, Early Silurian paleolatitude for central Newfoundland from paleomagnetism of the Wigwam Formation, Can. J. Earth Sci. 29, 1652-1661, 1992.

[8] J.P. Hodych and K.L. Buchan, Early Silurian palaeolatitude of the Springdale Group redbeds of central Newfoundland: A palaeomagnetic determination with a remanence anisotropy test for inclination error, Geophys. J. Int. 117, 640-652, 1994.

[9] B.J. Witzke, Paleoclimatic constraints for Paleozoic paleolatitudes of Laurentia and Euramerica, in: Paleozoic Paleogeography and Biogeography, W.S. McKerrow and C.R. Scotese, ed., Geol. Soc. London Mem. 12, 57-73, 1990.

[10] B.A. van der Pluijm, R. Van der Voo, S.S. Potts and J. Stamatakos, Early Silurian paleolatitude for Central Newfoundland from paleomagnetism of the Wigwam Formation: Discussion, Can. J. Earth Sci. 30, 644-645, 1993. 
[11] J. Stamatakos, R. Van der Voo, B.A. van der Pluijm, S.S. Potts and T. Torsvik, Comment on 'Early Silurian Paleolatitude of the Springdale Group Redbeds of Central Newfoundland: A Paleomagnetic Determination with a Remanence Anisotropy Test for Inclination Error', Geophys. J. Int., in press, 1994

[12] R.S. Coe, B.R. Globerman, P.W. Plumley and G.A. Thrupp, Paleomagnetic results from Alasika and their tectonic implications, in: Tectonostratigraphic Terranes, Pacific Northeast Quadrant, D.G. Howell, ed., pp. 85-108, Circ.-Pac. Counc. Energy Miner. Resour., Houston, Texas, 1986.

[13] T. Torsvik, A. Trench, J. Svensson and H.J. Walderhaug, Paleogeographic significance of mid-Silurian paleomagnetic results from southern Britain-major revision of apparent polar wander path for eastern Avalonia, Geophys. J. Int. 113, $651-668,1993$.

[14] H. Williams, Stratigraphy of the Botwood map area, northeastern Newfoundland, Geol. Surv. Can. Open File 113, 1972.

[15] M. Coyle and D. Strong. Geology of the Springdale Group: A newly recognized Silurian epicontinental-type caldera in Newfoundland, Can. J. Earth Sci. 24, 1135-1148, 1987.

[16] F.W. Chandler, R.W. Sullivan and K.L. Curric, The age of the Springdale Group, western Newfoundland, and correlative rocks-evidence for Llandovery overlap assemblage in the Canadian Appalachians, Trans. R. Soc. Edinburgh, Earth Sci. 78, 41-49, 1987.

[17] G.R. Dunning, S.J. O'Brien, S.P. Colman-Sadd, R.F. Blackwood, W.L. Dickson, P.P. O'Neill and T.E. Krogh, Silurian orogeny in the Newfoundland Appalachians, J. Geol. 98, $895-913,1990$.

[18] C.G. Elliot, G.R. Dunning and P.F. Williams, New U-Pb zircon age constraints on the timing of deformation in northcentral Newfoundland and implications for Early Paleozoic Appalachian orogenesis, Geol. Soc. Am. Bull. 103, 125-135, 1991.

[19] M. Coyle and D. Strong, Geology of the Springdale Caldera, Kings Point-Sheffield Lake Complex and spatially associated suites, Geol Surv. Can. Open File 2456, 1992.

[20] B.A. van der Pluijm, K.E. Kar]strom and P.F. Williams, Fossil evidence for fault-derived stratigraphy repetition in the northeastern Newfoundland Appalachians, Can. J. Earth Sci. 24, 2337-2350, 1987.
[21] B. LeFrance and P.F. Williams, Silurian deformation in eastern Notre Dame Bay, Newfoundland, Can. J. Earth Sci. 29, 1899-1914, 1992.

[22] J.L. Kirschvink, The least-squares line and plane and the analysis of paleomagnetic data, Geophys. J. Roy. Astron. Soc. $62,743-746,1980$.

[23] T. Torsvik, IAPD Interactive Analysis of Paleomagnetic Data, Int. Publ., Univ. Bergen, 1986.

[24] J.D.A. Zijderveld, A.C. demagnetization in rocks: Analysis of results, in: Methods of Paleomagnetism, D.W. Collinson, K.M. Creer and S.K. Runcorn, eds., pp. 254-286, Elsevier, Amsterdam, 1967.

[25] R.A. Fisher, Dispersion on a sphere, Proc R. Soc. London, Ser. A 217, 295-305, 1953.

[26] T. Schultz-Kurtisch and F. Heller, Measurement of magnetic susceptibility anisotropy in Buntsandstein deposits from southern Germany, J. Geophys. 56, 51-58, 1985.

[27] C. Richter and B.A. van der Pluijm, Separation of paramagnetic and ferrimagnetic susceptibilities using low-temperature magnetic susceptibilies and comparison with high field methods, Phys. Earth Planet. Inter. 82, 113-123, 1993.

[28] J.M. Parés, R. Van der Voo, J. Stamatakos and A. PerézEstaún, Remagnetization and post-folding oroclinal rotations in the Cantabrian/Asturian Arc, northern Spain, Tectonics, in press, 1994.

[29] E.A. Johnson, T. Murphy and O.W. Torreson, Pre-history of the Earth's magnetic field. Terr. Magn. Atmos. Electr. 53, 349-372, 1948.

[30] R.F. King, The remanent magnetism of artificially deposited sediments, Mon. Not. R. Astron. Soc., Geophys. Suppl. 7, 115-134, 1955.

[31] L. Tauxe and D.V. Kent, Properties of a detrital remanence carried by haematite from study of modern river deposits and laboratory redeposition experiments, Geophys. J. R. Astron. Soc. 77, 453-561, 1984.

[32] R. Lovlie and T. Torsvik, Magnetic remanece and fabric properties of laboratory-deposited hematite-bearing red sandstones, Geophys. Res. Lett. 11, 229-232, 1984.

[33] J. Stamatakos and K.P. Kodama, Flcxural flow folding and the paleomagnetic fold test: An example of strain reorientation of remanence in the Mauch Chunk Formation, Tectonics $10,807-819,1991$. 